\title{
A New Approach for LED Plant Growth Units
}

\author{
Ramazan Șenol, Kubilay Taşdelen
}

Suleyman Demirel University, Faculty of Technology, 32260, Isparta Turkey

ramazansenol@sdu.edu.tr, kubilaytasdelen@sdu.edu.tr

\begin{abstract}
This study aims to enable plant production even during sunless periods using a LED plant growth unit by controlling input variables such as temperature, soil humidity, atmospheric humidity, light intensity, wind speed, level of carbon dioxide in greenhouses and output variables such as lighting, cooling, heating, ventilation, irrigation by means of fuzzy logic control (FLC). It is expected that these indoor tests will provide means to grow plants such as tomato, pepper or cut flowers especially in regions that have sunless and cold winter months like Isparta. To this end, the design of the control unit, development of the Fuzzy rule base, and outline and simulations of the LED plant growth unit have been examined. The study focused on the factors affecting the greenhouse control such as ambient temperature, outside temperature soil humidity, $\mathrm{CO}_{2}$ production, wind speed, light intensity, heating, cooling, ventilation, irrigation, the LED plant growth unit as well as on the Fuzzy designs for lighting. The LED plant growth unit has been operated with direct current supply $(D C)$. The findings of the indoor tests carried out with the designed LED plant growth unit for pepper and aromatic chamomile are presented.
\end{abstract}

Keywords: LED plant growth unit; Intelligent light system; Greenhouse Automation

\section{Introduction}

Fluorescent lamps were used through long years in the development of plant growth units which were launched for the purpose of growing plants indoors or in greenhouses even at the times of no daylight. In recent years, more efficient and economic growth units started to be developed thanks to the developments in LED technology. Obtaining crops is not possible especially in the greenhouses where cut flower is grown, in the regions that have sunless and cold winter months. This situation creates an negative economic impact on the producers planting in the greenhouses. In recent years, LED products have come into our lives swiftly thanks to the innovations and changes in LED technology in a large number of sectors from informatics to lighting. Higher definition and resolution TVs or monitors, more efficient and economic lighting units have been rapidly spreading. The usage of LED units instead of traditional lighting units becomes not only economic, but also decorative. LED lighting units supercede fluorescent or 
energy-saving lamps thanks to their longevity and low negative health effects. The increase in LED choice for lighting especially in offices and factories has reached a considerable level. Furthermore, LED plant growth units were swift to supercede fluorescent and halogen lamps. Formerly, LED plant growth units did not look promising because of low lighting efficiency. Nevertheless, thanks to recent technological developments and better longevity and lighting efficiency in LED lighting units, LED plant growth units came to the fore again. In fact, studies have been performed within the scope of NASA's Advanced Exploration Systems (AES) at Kennedy Space Center's Space Life Sciences Laboratory. The main purpose of a greenhouse is to improve the environmental conditions in which plants are grown. In greenhouses provided with the appropriate equipment, these conditions can be further improved by means of climate control [1]. Modern greenhouse and computerized climate control modules have become inseparable nowadays. Computerized climate control is an intrinsic part of present day modern greenhouse [2]. Some of the advantages of FLC systems in greenhouses are improvements in crop quality, harvest, energy saving [3], as well as in the reduction of the human factor [4]. The main environmental factors affecting the greenhouse climate control are as follows: temperature, relative humidity, of the inside air; vapor pressure deficit, transpiration [5], sunlight, $\mathrm{CO}_{2}$ generation, wind speed [6] and lighting. The Output Unit Models for the greenhouses are heating system, cooling system, irrigation systems, mechanical fan, fog cooling and Lighting System [1].

In this study, a fuzzy controlled greenhouse model was set ,and the performance of the growth lamp designed with LEDs of different wave lengths and colors was examined. Parameters such as soil humidity, ambient temperature and humidity, exterior ambient temperature and humidity, wind speed, radiation doses under interior ambient and growth unit and interior carbon dioxide level were measured and processed as fuzzy rule-based. Accordingly, heating, ventilation, irrigation and shadowing of the greenhouses and scaling the light level of the LED growth unit were experimented. All measurement and control parameters were recorded on the MMC card found on the control unit. The performance of the developed control unit and the LED growth unit and its effect on pepper were examined indoors.

\section{Material and Method}

\subsection{Modeling The Greenhouse}

The greenhouse controller block diagram, which is integrated into the system model recommended by Javadikia et all 2009, is seen in Figure 1 [1]. 


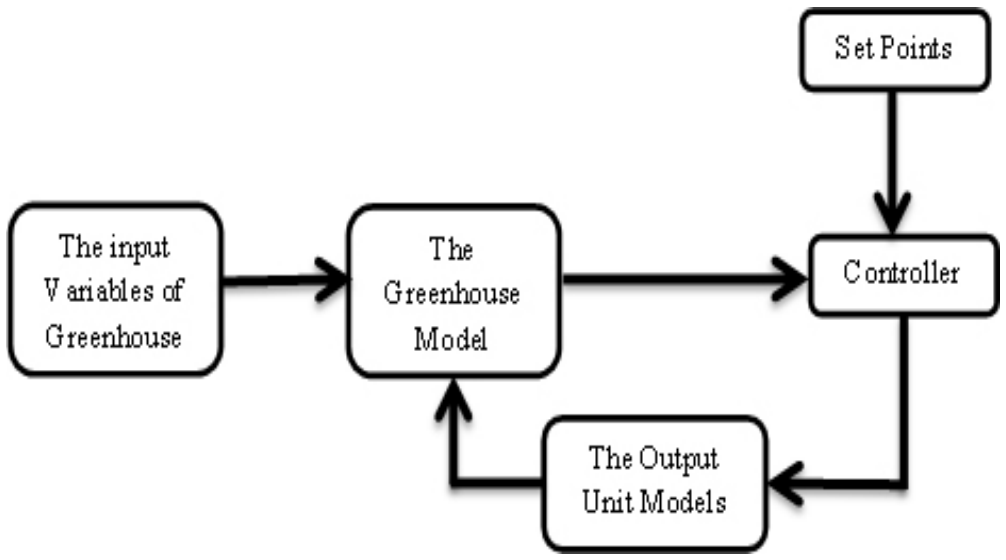

Figure 1

Greenhouse controller block diagram

The total area of the prototype greenhouse is set to 2 square meters. In the set model, input variables are light intensity, temperature, air humidity, soil humidity, wind speed and carbon dioxide level. As for output variables, identification of the light intensity of the LED plant growth unit, irrigation, heating, cooling, and ventilation are handled. Shadowing is not considered in the developed model. Since the aim of the model is to provide artificial light into the greenhouse especially during sunless periods, the need for shadowing is eliminated. However, taking summer into consideration, an output was designed on the control card output for controlling the shadowing unit. Chao and Gates [7] reviewed recent models for greenhouses, from which we take the following dynamic equations for interior air temperature. Note that conversion of sensible heat to latent heat is accounted for by using a "net" sensible heat term in each equation. A greenhouse dynamic equation is [1];

$\rho C_{p} V \frac{\partial T}{\partial t}=\left(q_{h}+a S A_{f}\right)-\rho C_{p} \dot{V}\left(T-T_{\text {out }}\right)-U A_{s}\left(T-T_{\text {out }}\right)$

Variables in these equations are defined as:

$A_{f}=$ floor area $\left(\mathrm{m}^{2}\right)$

$A_{s}=$ surface area $\left(\mathrm{m}^{2}\right)$

$a=$ building net solar heating efficiency

$C_{p}=$ specific heat of air $\left[\mathrm{J}\left(\mathrm{kg}^{\circ} \mathrm{C}\right)^{-1}\right]$

$q_{h}=$ heater output $(\mathrm{W})$

$\rho=$ air density $\left(\mathrm{kg} \mathrm{m}^{-3}\right)$

$S=$ solar irradiance $\left(\mathrm{W} \mathrm{m}^{-2}\right)$
$T^{n}=$ interior air temperature $\left({ }^{\circ} \mathrm{C}\right)$

$T_{\text {out }}=$ outside air temperature $\left({ }^{\circ} \mathrm{C}\right)$

$U=$ overall building thermal conductance $\left(\mathrm{W} \mathrm{m}^{-2}{ }^{\circ} \mathrm{C}^{-1}\right)$

$V$ = building volume $\left(\mathrm{m}^{3}\right)$

$\dot{V}=$ volumetric ventilation rate $\left(\mathrm{m}^{3} \mathrm{~s}^{-1}\right)$ 


\subsection{Traditional Climate Control}

This control system is based on a heater actuator which is turned on and turned off by a thermostat whenever the temperature error is oversteps the fixed regulation band. The humidity depends on the internal air temperature and the ventilation rate. This last variable is regulated by opening the windows of the greenhouse, based on the measured wind-speed. This also avoids some dangerous situations such as high wind speed in the external environment [8].

\subsection{Fuzzy Logic Climate Control}

As known from the Fuzzy Logic principles an FLC acts as a non-linear system implementing a human-based reasoning for the computation of their output values [8]. Fuzzy knowledge-based systems are one of the most successful applications of fuzzy sets and fuzzy logic methods. This is mainly due to the flexibility and simplicity by which knowledge can be expressed using fuzzy rules as well as to the theoretical developments in this field [9]. The fuzzy rule base consists of a collection of fuzzy IF-THEN rules. The basic configuration of a fuzzy logic system for a greenhouse is shown in Figure 2. The features and Fuzzy linguistic expressions of input/output system variants are given in Table 1 and Table 2.

Table 1

The Fuzzy linguistic expressions of input /output system variants

\begin{tabular}{|l|l|l|}
\hline Parameters & Type & Fuzzy Linguistic expressions \\
\hline Ambient Temperature & Input & Very Low, Low, Medium, High, Very High \\
\hline Inside Temperature & Input & Very Low, Low, Medium, High, Very High \\
\hline Air Humidity & Input & Very Low, Low, Medium, High, Very High \\
\hline Soil Humidity & Input & Very Low, Low, Medium, High, Very High \\
\hline $\mathrm{CO}_{2}$ & Input & Very Low, Low, Medium, High, Very High \\
\hline Wind Speed & Input & Very Low, Low, Medium, High, Very High \\
\hline Lighting & Input & Very Low, Low, Medium, High, Very High \\
\hline Heating System & Output & Very Low, Low, Medium, High, Very High \\
\hline Cooling System & Output & Very Low, Low, Medium, High, Very High \\
\hline Irrigation System & Output & Very Low, Low, Medium, High, Very High \\
\hline LED plant Growth Unit & Output & Very Low, Low, Medium, High, Very High \\
\hline Mechanical Fan & Output & Very Low, Low, Medium, High, Very High \\
\hline
\end{tabular}


Table 2

The Features of input /output system variants

\begin{tabular}{|l|l|l|l|}
\hline Parameters & Min & Max & Denomination \\
\hline Ambient Temperature & -20 & 40 & ${ }^{\circ} \mathrm{C}$ \\
\hline Inside Temperature & -20 & 50 & ${ }^{\circ} \mathrm{C}$ \\
\hline Air Humidity & 0 & 100 & $\%$ \\
\hline Soil Humidity & 0 & 100 & $\%$ \\
\hline $\mathrm{CO}_{2}$ & 0 & 2000 & $\mathrm{ppm}$ \\
\hline Wind Speed & 0 & 10 & $\mathrm{~m} / \mathrm{s}$ \\
\hline Lighting & 0 & 20000 & $\mathrm{Lux}$ \\
\hline Heating System & 0 & 3 & $\mathrm{~kW}$ \\
\hline Cooling System & 0 & 20 & $\mathrm{Micron}$ \\
\hline Mechanical Fan & 0 & 50 & ${ }^{\circ}$ \\
\hline Irrigation System & 0 & 20 & $\mathrm{Lt}$ \\
\hline LED plant Growth Unit & 0 & 20000 & $\mathrm{Lux}$ \\
\hline
\end{tabular}

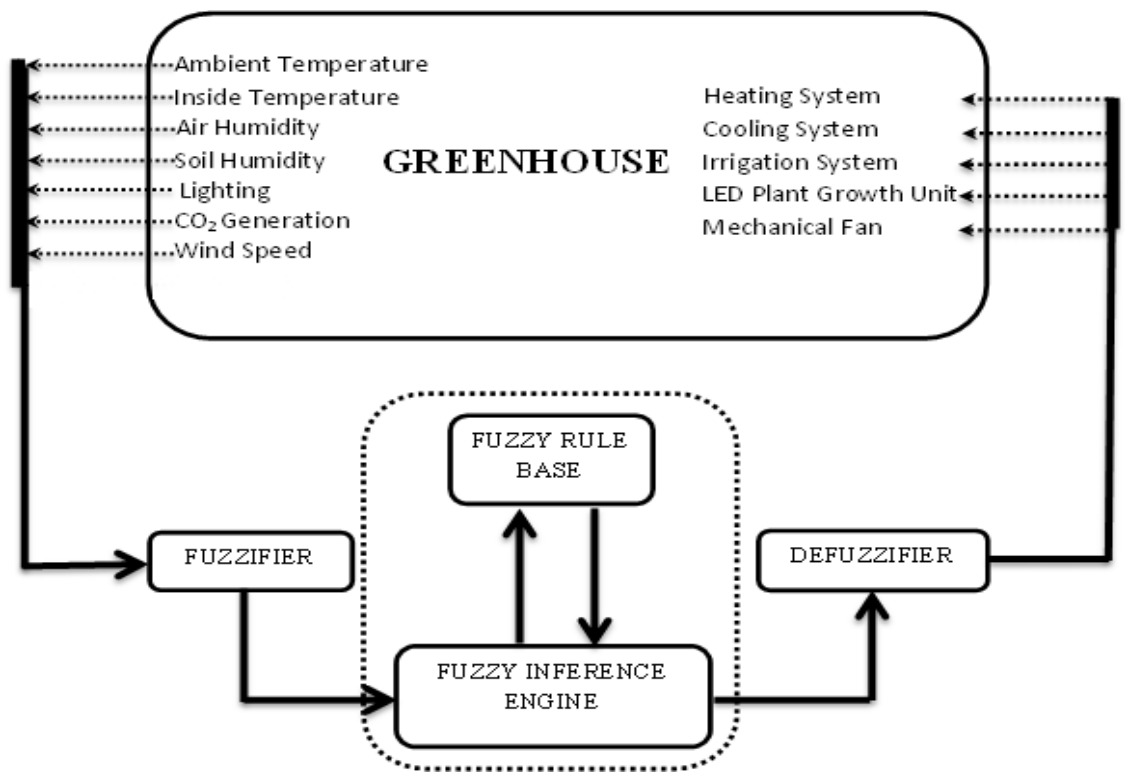

Figure 2

The Fuzzy control system model designed for the greenhouse system

For all the Fuzzy inferences, the Mamdani inference model was preferred as it is both easy and suitable for the greenhouse model. The triangle fuzziness method was chosen. Reference situations for tests were chosen according to growing conditions. Relying on expert opinion, the value of soil humidity was determined 
to be $70 \%$, the need for light as 10000 Lux, ambient temperature in the greenhouse as $24{ }^{\circ} \mathrm{C}$. Fuzzification of the input signs which belong to these specified parameters is given in Figure 3.

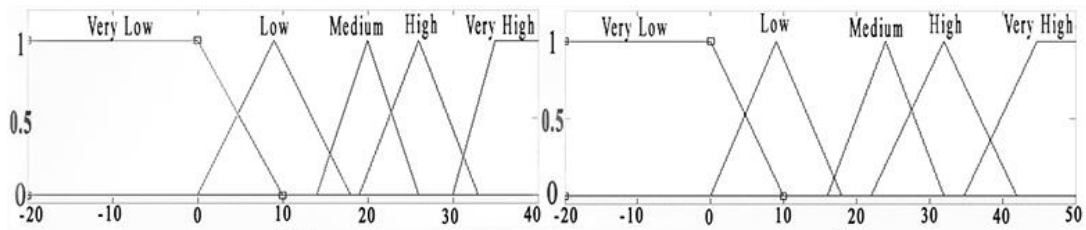

(a)

(b)

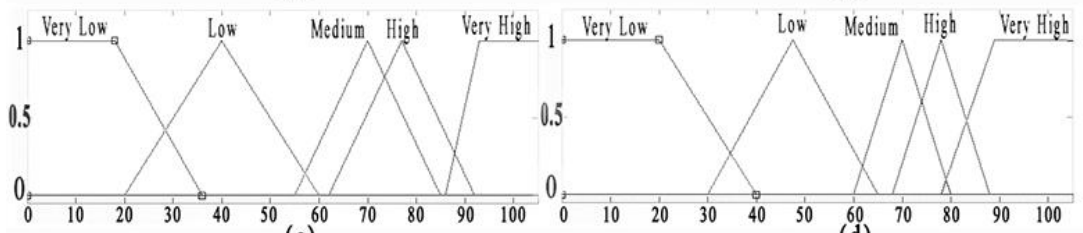

(c)

(d)

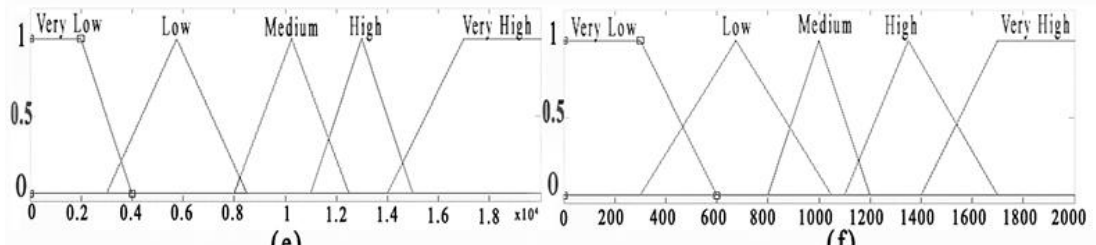

(e)

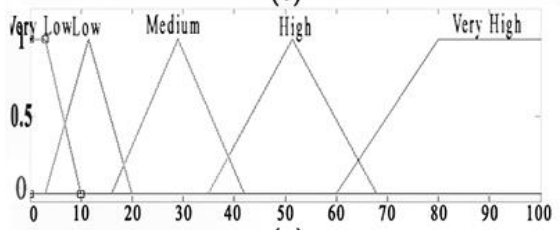

(g)

a-Ambient Temperature

(f)

b-Inside Temperature

c-Air Humidity

d-Soil Humidity

e-Lighting

f- $\mathrm{CO}_{2}$

g-Wind Speed

Figure 3

Fuzzification of input operating conditions

Fuzzification of the output signs for the specified output parameters (heating, cooling, ventilation, lighting, irrigation) is given in Figure 4. Since the tests were carried out indoors, parameters such as the measurement of the wind speed and the level of light which comes into the greenhouse from the outside were not considered. Wind speed and level of light parameters which exist on the rule base were deactivated during the experiments. How the exterior light intensity that comes into the greenhouse affects the output of the LED plant growth unit is given in Table 3. The control logic of the LED plant growth unit is mentioned in the control section. 
Table 3

Effect of light intensity to LED plant growth unit output parameters

\begin{tabular}{|l|l|}
\hline Light Intensity & LED plant growth unit output \\
\hline Very Low & Very High \\
\hline Low & High \\
\hline Medium & Medium \\
\hline High & Low \\
\hline Very High & Very Low \\
\hline
\end{tabular}

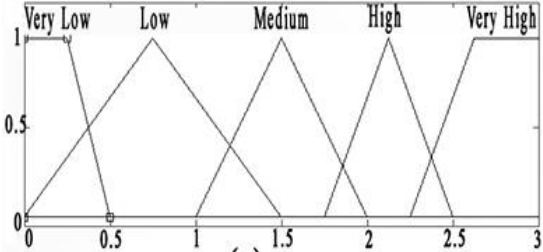

(a)

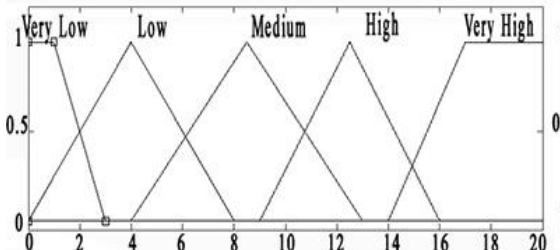

(c)

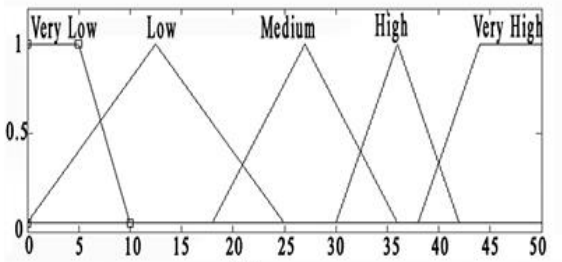

(e)

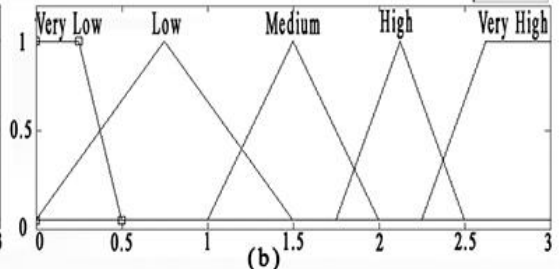

(b)

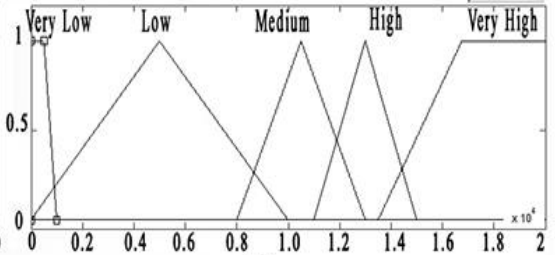

(d)

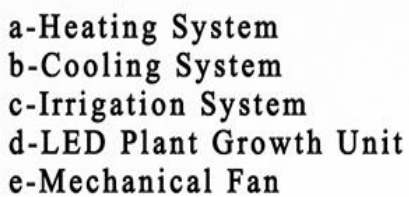

Figure 4

Fuzzification of output operating conditions

\subsection{LED Plant Growth Unit}

The designed LED plant growth unit is composed of Royal Blue, Blue, UVA, Far Red and Red LEDs. Total electric power consumption of the unit which is composed of power LEDs of $3 \mathrm{~W}, 5 \mathrm{~W}$ and $10 \mathrm{~W}$ is $217 \mathrm{~W}$. Direct current fans used for cooling increases this value to $220 \mathrm{~W}$. Power LEDs were installed on the aluminum PCBs, whose features are given in Table 4. 
Table 4

Features of the aluminum PCB

\begin{tabular}{|l|l|l|}
\hline Power LED PCB & Model 1 & Model 2 \\
\hline Diameter & $100 \mathrm{~mm}$ & $120 \mathrm{~mm}$ \\
\hline LED Pieces & 9 & 12 \\
\hline Ground Color & White & White \\
\hline Number of PCB & 1 & 6 \\
\hline
\end{tabular}

Power LED layout for settlement in Figure 5 shows the design for obtaining an effective lighting design and effective air cooling. Thanks to the established lighting layout, a light source which has a wave length of 380-385 nm with Ultra Violet UVA, 455-457.5 nm with Royal Blue power led, 460-475 nm with Blue power led, 615-630 nm with Red power led, and $660 \mathrm{~nm}$ with Far Red power led, was set. Electrical features of the power LEDs that were used are given in Table 5. Emission spectra of red (R) and blue (B) LEDs is given in Figure 6a.

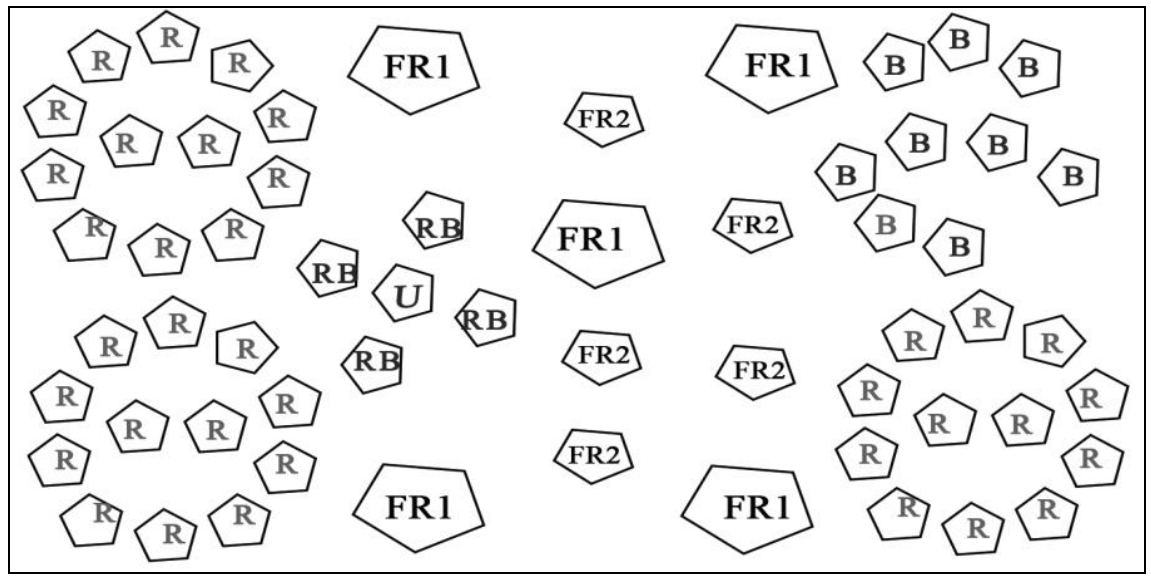

Figure 5

The settlement of the power LEDs which have different wavelengths in the LED plant growth unit

Table 5

Electrical features of the power LEDs which have different wave lengths in the LED plant growth unit

\begin{tabular}{|l|l|l|l|l|l|l|}
\hline Index & $\boldsymbol{R B}$ & $\boldsymbol{B}$ & $\boldsymbol{U}$ & $\boldsymbol{R}$ & $\boldsymbol{F R \boldsymbol { I }}$ & $\boldsymbol{F R 2}$ \\
\hline Name & $\begin{array}{l}\text { Royal } \\
\text { Blue }\end{array}$ & Blue & $\begin{array}{l}\text { Ultra Violet } \\
\text { UVA }\end{array}$ & Red & Far Red & Far Red \\
\hline Power (Watt) & 3 & 3 & 5 & 3 & 10 & 3 \\
\hline Pieces & 4 & 9 & 1 & 36 & 5 & 5 \\
\hline Rate of Radiation & 5,53 & 12,44 & 2,30 & 49,76 & 23,04 & 6,91 \\
\hline Wavelength (nm) & $\begin{array}{l}455 \\
457.5\end{array}$ & $\begin{array}{l}460 \\
475\end{array}$ & $380-385$ & $\begin{array}{l}615 \\
630\end{array}$ & 660 & 660 \\
\hline
\end{tabular}




\begin{tabular}{|l|l|l|l|l|l|l|}
\hline Intensity (Lm) & $30-40$ & $25-32$ & $\begin{array}{l}400-600 \\
(\mathrm{MW} / \mathrm{sq})\end{array}$ & $65-75$ & 300320 & $70-80$ \\
\hline $\begin{array}{l}\text { Viewing Angle } \\
\text { (Degree) }\end{array}$ & 120 & 140 & $115-125$ & 140 & 180 & 120 \\
\hline Forward Voltage (V) & $3.4-3.6$ & $3.2-4.0$ & $6.5-7.5$ & $2.2-3.0$ & $7.0-9.0$ & $2.7-3.0$ \\
\hline $\begin{array}{l}\text { Average Forward } \\
\text { Current (mA) }\end{array}$ & 700 & 700 & 750 & 700 & 1000 & 750 \\
\hline
\end{tabular}

Power LEDS were soldered onto the aluminum PCBs as shown in Figure 5 with special thermal paste, the features of which are given in Table 6. Aluminum PCBs were mounted on the aluminum coolers with special thermal paste, the features of which are given in Table 7. Thermal grease helps to disperse the heat from aluminum PCB to the heat sink effectively. It has a high temperature resistance. It is non-toxic, tasteless and non-corrosive. The heat on the surface is rejected from the surface due to the DC fans which were mounted on the back surface of aluminum coolers.

Table 6

The features of Gold Thermal Grease Paste

\begin{tabular}{|l|l|}
\hline \multicolumn{2}{|l|}{ Gold Thermal Grease Paste } \\
\hline Thermal Conductivity $(\mathrm{W} / \mathrm{m}-\mathrm{k})$ & $>3$ \\
\hline Thermal Resistance $\left({ }^{\circ} \mathrm{C}-\mathrm{in}^{2} / \mathrm{W}\right)$ & $<0.123$ \\
\hline Color & Gold \\
\hline
\end{tabular}

Table 7

White Thermal Compound Grease

\begin{tabular}{|l|l|}
\hline \multicolumn{2}{|l|}{ Thermal Compound Grease Paste } \\
\hline Thermal Conductivity $(\mathrm{W} / \mathrm{m}-\mathrm{k})$ & $>0.65$ \\
\hline Thermal Resistance $\left({ }^{\circ} \mathrm{C}-\mathrm{in} 2 / \mathrm{W}\right)$ & $<0.262$ \\
\hline Color & White \\
\hline
\end{tabular}

LED plant growth unit's height is 2 meters from the ground. The sides of the closed area were covered with Mylar film and was aimed for more effective lighting. The Mylar film has 175 micron in thickness, high reflectance, very high level of thermo stability, and further, is easy to clean. Mylar Film, commonly used in wall covering material by the indoor cultivators, is a reflective product. It also enables the use of each watt of energy spent by the lighting unit. In the case of using aluminum foil as the wall covering material, the zigzags on the aluminum foils cause extremely hot spots and these hot spots could have a lens effect, focusing the light on certain parts of the plant resulting in burn spots. Holding a smooth structure, Mylar film does not result in hot spots and is preferred for indoor studies. 


\subsection{Control Unit}

PIC microprocessor 18F4550 which was produced by Microchip Company was chosen as the controller in the control unit. Sensors were connected to the ports of controller. These include one temperature sensor (DS18B20) to measure outer ambient temperature, one humidity sensor (SHT11) to measure soil humidity and temperature, one humidity sensor (SHT11) to measure in-greenhouse ambient humidity and temperature, one photo diode (S1223) to measure the level of light coming from outside into the greenhouse, one photo diode (S1223) to measure the total level of light coming from outside and LED plant growth unit into the greenhouse and one Carbon dioxide sensor (MG811) to measure the level of carbon dioxide in the greenhouse. The measured light values were amplified with the opamp and applied to the controller. The spectral sensitivity of the photo diode (PD) from the S1223 datasheet is shown in Figure 6b. The connection was made by the mosfets to enable the outputs of heating, cooling, irrigation, ventilation system and the output of the LED plant growth unit light control to the ports of the controller which was directed as output. Thanks to the mosfets output units on the control card, the parameters such as heating, cooling, ventilation, irrigation, lighting can be controlled according to PWM.

Schematic representation of the control system is given in Figure 7. Thanks to the LCD indicator on the control card, the instant values of the system in the greenhouse can be monitored. All the components of the system can be monitored from a distance by computer connection. Temperature, humidity, irradiation values and heating, cooling, irrigation, ventilation and lighting event times are recorded on the MMC unit on the card. The parameters such as irrigation, ventilation, heating and lighting can be controlled using PWM.

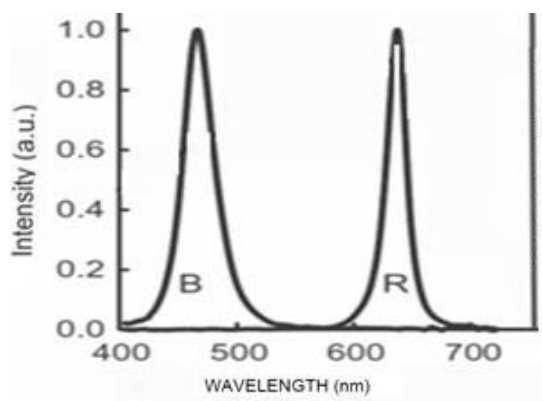

a)

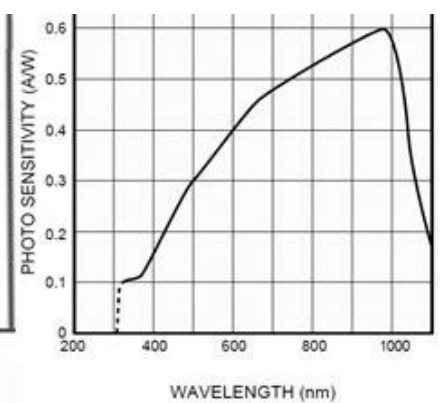

b)

Figure 6

a) Emission spectra of red (R) and blue (B) LEDs

b) The spectral sensitivity curve of the photodiode (PD) from the S1223 datasheet is shown 


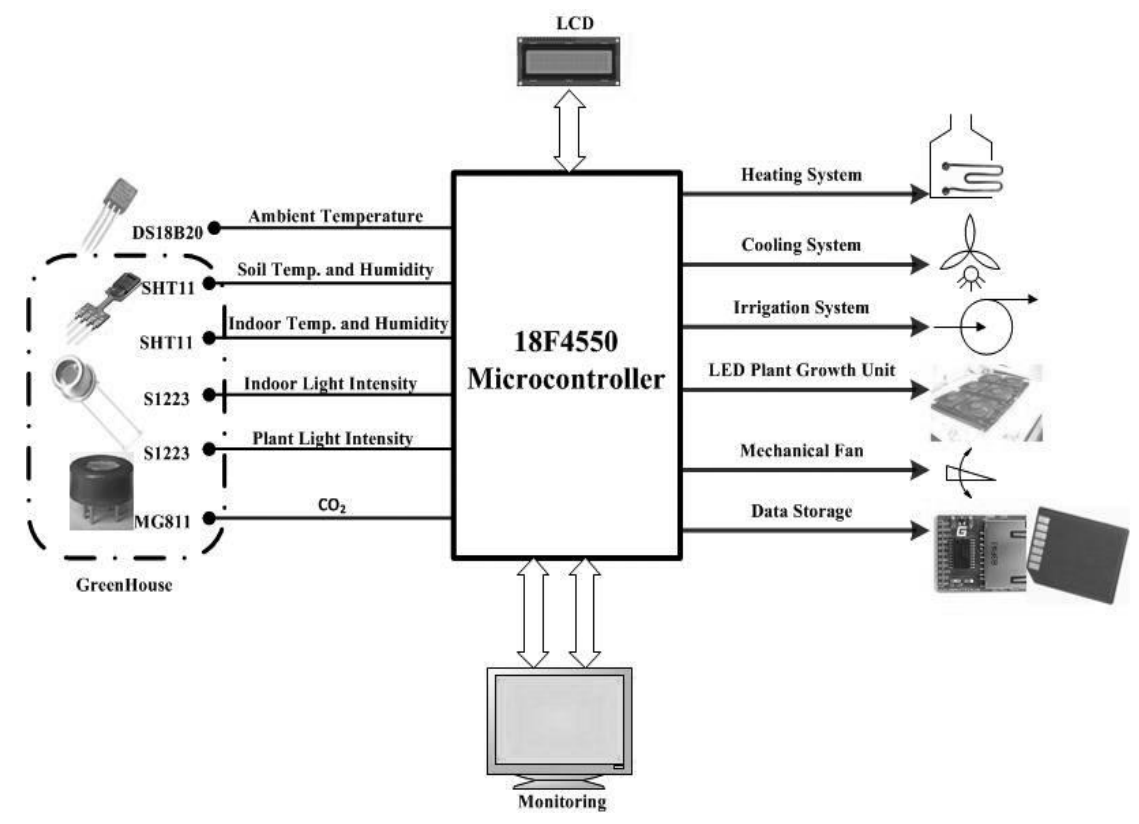

Figure 7

Schematic representation of the control system

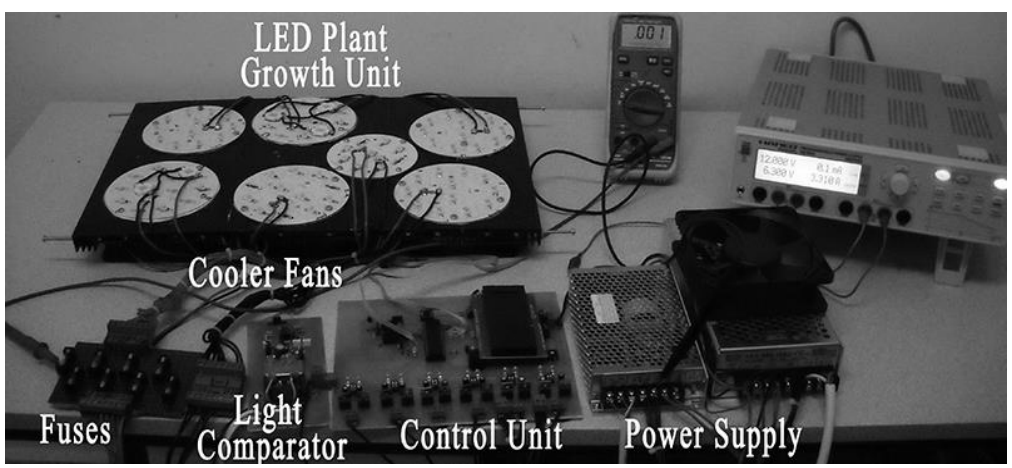

Figure 8

LED plant growth unit and control equipment

A scene from the test period of the LED plant growth unit and control card is given in Figure 8. The programmable Hameg HMP2020 power supply was used for current tests. Almemo UVA probe head FLA 603 UV12, lux probe head FLA 603 and an irradiation unit that were developed using S1223 photodiodes were used for radiometry measurements. Almemo FHAD 46 series humidity sensor was used for the calibration of SHT11 sensor which was used for humidity and temperature and DS18B20 sensor. SHT11 sensor used for soil humidity and 
temperature was mounted into a pointed copper tube. Holes were made on the pointed side of the copper tube and then it was placed into soil. The back part of the copper tube was insulated to make sure it was not affected by the outer conditions.

\subsection{Experiments}

The growth chamber model for LED plant growth unit is given in Figure 9. For three weeks pepper plants were grown in a 2-square-meter closed area that was 2 meters high, with an average day temperature of $25^{\circ} \mathrm{C}$ and a night temperature of $19^{\circ} \mathrm{C}$. The sides and ground of the closed area were covered with Mylar film and pepper and aromatic chamomile were placed in it. The parameters such as humidity and temperature values, soil temperature and humidity, light intensity, the level of carbon dioxide in the area were measured and saved in MMC. Plants were exposed to 16 hours of lighting every day. The average indoor light intensity was 10000 Lux. All operation conditions and measured values were recorded on an MMC card in real time with the integration of the real time clock (DS1307) of the control card. While ventilation should be carried out using a mechanical fan in a real greenhouse, it was instead provided with the help of direct current fans in the constructed mechanism. A mini DC pump, the water hole diameter of which was $4 \mathrm{~mm}$, was used for drip irrigation. In addition, the atomized system involving a pump and nozzles was used to balance the ambient humidity. This system atomized water to the interior area when the humidity was low.

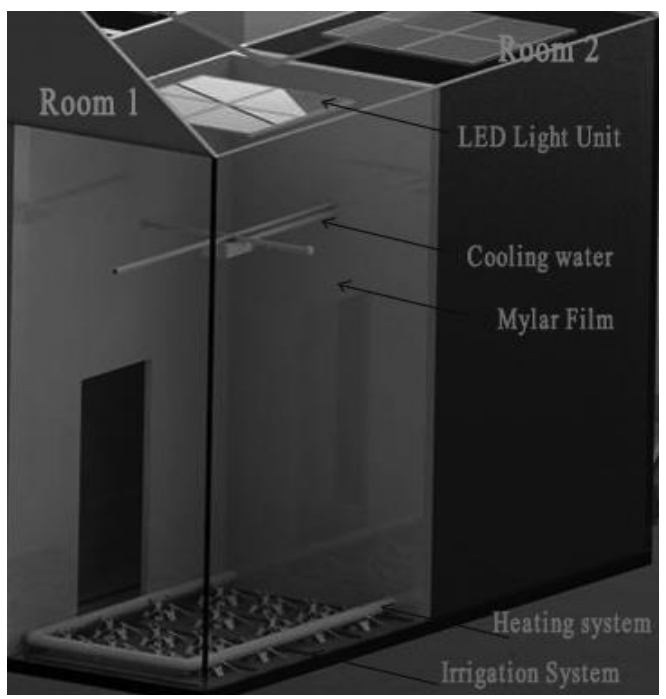

Figure 9

The appearance of the testing apparatus 
LED plant growth unit was supplied in constant supply mode during the experiments. In other words, each led in the LED plant growth unit and the features given in Table 5 had constant current supply. Thus, there was constant light, which has a wave length varying between $380 \mathrm{~nm}$ and $660 \mathrm{~nm}$, of $10 \mathrm{~K} \mathrm{Lux}$. The growth values of pepper and aromatic chamomile are given in Figures 10 and 11. In Figure 12, pepper and aromatic chamomile growth phase periods in the 19.04.2013 and 10.05.2013 labeled a-b-c and d-e-f.
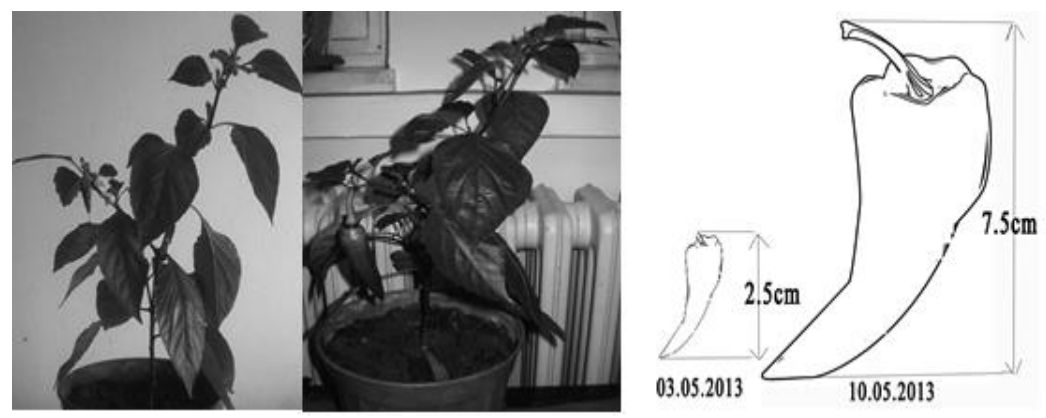

Figure 10

Pepper plant growth

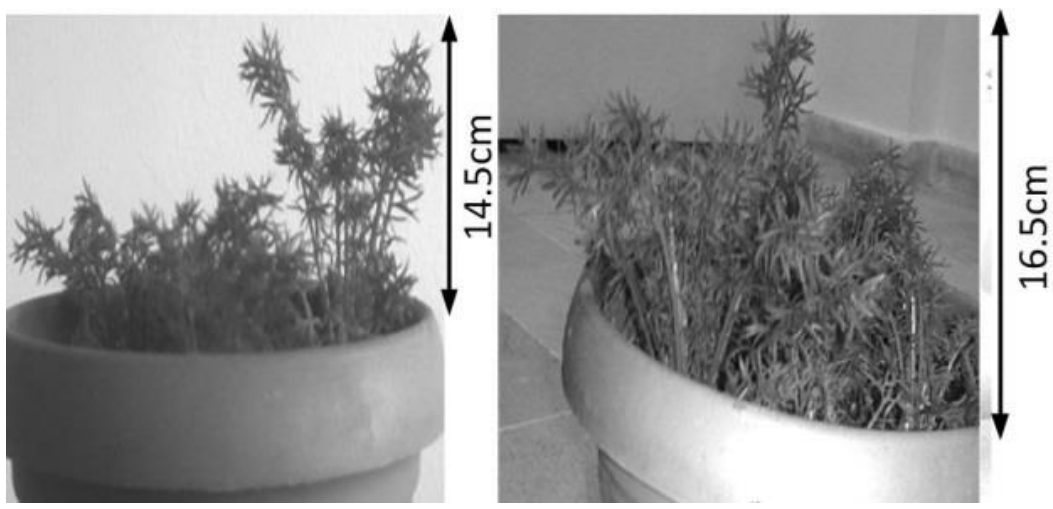

Figure 11

Aromatic Chamomile plant growth 


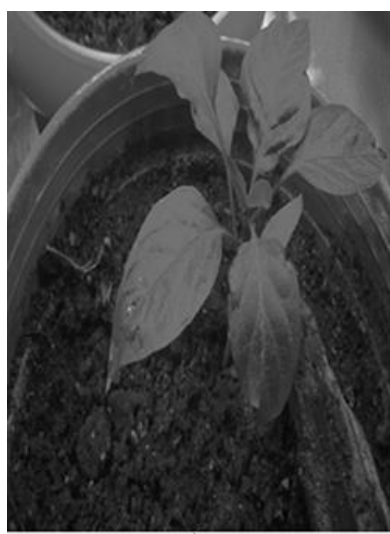

a)

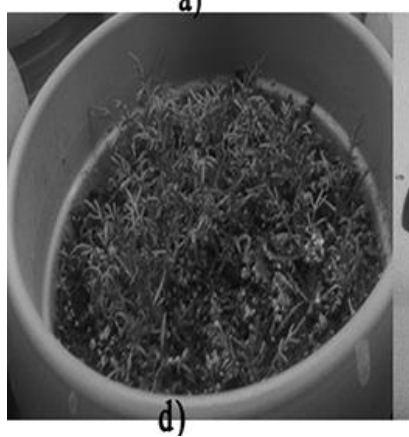

d)

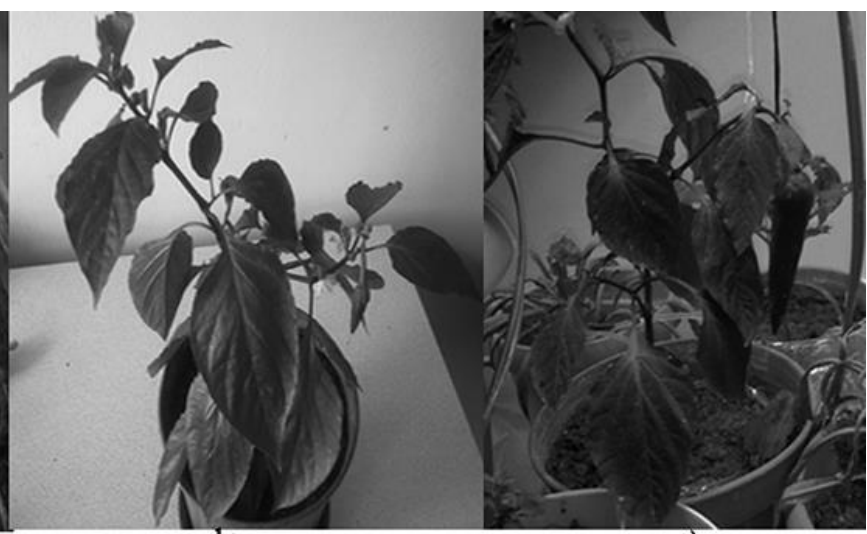

b)

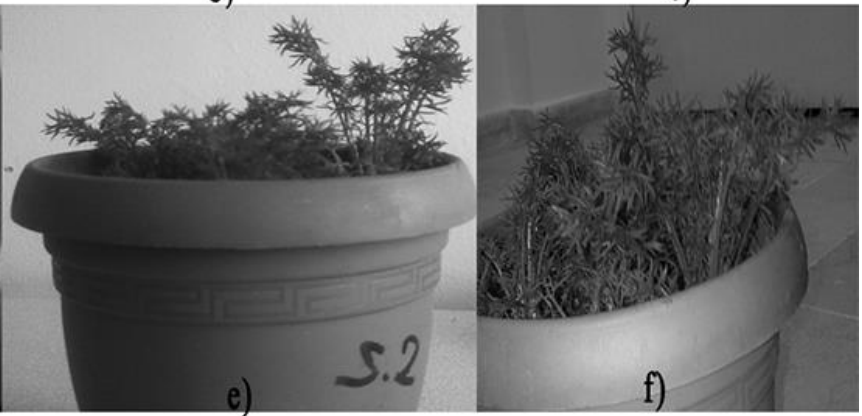

Figure 12

Pepper and Aromatic Chamomile plant growth

a) 19.04.2013 pepper, b) 03.05.2013 pepper, c) 10.05.2013 pepper, d) 19.04.2013 Aromatic

Chamomile, e) 03.05.2013 Aromatic Chamomile, f) 10.05.2013 Aromatic Chamomile

\section{Conclusions}

Fuzzy control can reduce the financial costs in the greenhouses. While the quality of the crops is increased, energy costs are reduced in a greenhouse controlled via fuzzy logic method. The indoor plant growth cabin with fuzzy logic-based control suggested in the study was designed for the purpose of growing plants in the greenhouses when there is not enough light during winter months. In the indoor experiments, only the parameters such as light, temperature, humidity, carbon dioxide were taken as input. In the rule base, the fuzzy logic method was applied in accordance with the working conditions of a real greenhouse. Output parameters were irrigation, ventilation and lighting. Factors like heating and cooling were not considered in the controlled indoor environment. The results that were obtained from pepper and aromatic chamomile are presented above.

Since the main objective of the study is to ensure carnation production in greenhouses during winter, later experiments shall involve greenhouse conditions 
for growth of carnation. Alternate energy sources like soil source heat pump as well as biomass shall be used to produce heating energy needed during winter.

In the study, a DC constant supply condition was considered. As for the ongoing designs, new growth units are worked on to examine two different working conditions simultaneously. The upcoming studies will discuss the experiments conducted with existing control card and control mechanism on the plants that are tested by one LED plant growth unit with PWM output and by another LED plant growth unit with constant DC supply. Thus, the development process and crop yield of the plants which are grown in PWM mode and with DC constant supply will be examined. Finally, the effect of different PWM parameters on plants will be studied.

\section{References}

[1] Javadikia, P., Tabatabaeefar, A., Omid, M., Alimardani, R., Fathi, M. (2009) Evaluation of Intelligent Greenhouse Climate Control System-based Fuzzy Logic in Relation to Conventional Systems. International Conference on Artificial Intelligence and Computational Intelligence, pp. 146-150

[2] Straten, G. V. (1999) Acceptance of Optimal Operation and Control Methods for Greenhouse Cultivation. Annual Reviews in Control, Vol. 23, pp. $83-90$

[3] Seginer, I., Zlochin, I. (1997) Night-Time Greenhouse Humidity Control with a Cooled Wetness Sensor. Agricultural and Forest Meteorology, Vol. 85, pp. 269-277

[4] Collewet, C., Rault, G., Quellec, S., Marchal, P. (1998) Fuzzy Adaptive Controller Design for the Joint Space Control of an Agricultural Robot. Fuzzy Sets and Systems, pp. 1-25

[5] Joliet, O., Hortitrans (1994) A Model for Predicting and Optimizing Humidity and Transpiration in Greenhouse, Journal of Agricultural Engineering. Vol. 57, No. 1, pp. 23-37

[6] Körner, O., Challa, H. (2003) Process-based Humidity Control Regime for Greenhouse Crops. Computers and Electronics in Agriculture, pp. 1-20

[7] Chao, K., Gates, R. S. (1996) Design of Switching Control Systems for Ventilated Greenhouses, Trans ASAE, Vol. 39, No. 4, pp. 1513-1523

[8] Caponetto, R., Fortuna, L., Nunnari, G., Occhipinti, L. (1998) A Fuzzy Approach to Greenhouse Climate Control, Proceedings of the American Control Conference, Philadelphia, Pennsylvania, pp. 1866-1870

[9] Salgado, P., Cunha, JB. (2005) Greenhouse Climate Hierarchical Fuzzy Modelling. Control Engineering Practice 13, 613-628 